\title{
Effects of a multimodal activation program (SimA-P) in residents of nursing homes
}

\author{
W. D. Oswald • T. Gunzelmann • A. Ackermann
}

Received: 27 October 2006 / Accepted: 11 July 2007 /Published online: 31 July 2007

(C) EGREPA 2007

\begin{abstract}
Is it possible to maintain or even enhance functional and cognitive independence in residents of nursing homes? Little is known about the potentials and limits of therapeutic methods designed to maintain independence in elderly people already in need of residential nursing care. The aim of the "Rehabilitation in Nursing Homes" research project was to determine the practicability and effectiveness of a rehabilitative approach targeting residents of nursing homes. The main objectives of the activation program were to maintain and enhance residents' cognitive and functional autonomy. Data on psychological, functional, and medical variables were obtained from a sample of 294 nursing home residents (age range $=70-99$ years) at three points of measurement over a 12-month period. The intervention approach draws on the theoretical and practical findings of the SimA Study ("Bedingungen der Erhaltung und Förderung von Selbstständigkeit im höheren Lebensalter," "conditions on maintaining and supporting independent living in old age"; Oswald et al., Z. Gerontopsychol. Psychiatr., 15:61-84, 2002, Z. Gerontopsychol. Psychiatr., 15:13-31, 2002) and incorporates the results of recent therapeutic and rehabilitative
\end{abstract}

The research for this article was conducted as part of the

"Rehabilitation in Nursing Homes" project, which was funded by the German Federal Ministry of Health and Social Security (BMGS 52458640). The authors are responsible for the content of the article.

W. D. Oswald · T. Gunzelmann • A. Ackermann

FG Prävention \& Demenz am Institut für Psychogerontologie der Universität Erlangen Nürnberg,

Erlangen, Germany

\section{A. Ackermann ( $\square)$}

FG Prävention \& Demenz am Institut für Psychogerontologie der Univesität Erlangen-Nürnberg,

Wallensteinstr. 61-63,

90431 Nuremberg, Germany

e-mail: forschung@wdoswald.de studies in the fields of geriatrics and gerontopsychiatry. The intervention involves a combined program of cognitive and physical activation. An alternative program based on biographical information was designed specifically for residents with dementia. Results show that the intervention had significant effects on cognitive and functional parameters. Moreover, transfer effects were observed with respect to activities of daily living and frequency of falls.

Keywords Nursing homes · Rehabilitation .

Cognitive activation $\cdot$ Fall prevention .

Activities of daily living

\section{Rehabilitation in nursing homes}

Most residents of nursing homes are elderly people in need of regular or around-the-clock nursing care [43]. Some $80 \%$ of the residents of nursing homes for the elderly have impaired mobility, $80 \%$ show cognitive impairment, and 70\% experience symptoms of depression. Against this background, rehabilitative approaches to care [12] seek to maintain, enhance, or restore functional ability, or at least to prevent or delay the deterioration or loss of functioning and to help individuals adapt to irreversible losses in functional capacity.

Epidemiological studies show that need for care is not determined by physical impairment or illness alone. In fact, it is characterized by multiple factors such as multimorbidity, mobility problems, cognitive impairment, psychological symptoms (primarily depression), and social isolation [25, 40, 52]. Accordingly, multimodal intervention programs that target physical exercise and cognitive performance while, at the same time, promoting psychological well-being and social interaction should be most likely to have rehabilitative effects [1]. 
Improving physical performance

The major dimensions of physical fitness and mobility are strength, stamina, suppleness, and coordination [34]. Because they involve both physical and psychological factors, these motor demands are also termed "psychomotor skills" [34]. Research has shown that physical training can enhance these skills and thus delay or decrease the need for assistance or care, even in individuals who are already frail or have chronic health problems [7, 46, 50, 59]. Furthermore, such interventions reduce the physical risk factors contributing to falls, such as decline in lower body strength and mobility, postural disorders, and reduction in balance ability [45]. Given that falls are known to be one of the major risk factors for becoming (more) dependent on care $[4,49]$, physical activation has a major role to play in rehabilitative care. Training programs that combine strength and balance training to improve mobility can significantly reduce the frequency of falls $[5,8,22,33,35]$. Programs of this kind have proved to have positive effects on the functional performance and psychological state of nursing home residents $[9,44]$. Likewise, physical training has also been shown to have beneficial effects on the strength, balance, reaction time, and flexibility of individuals with dementia [31]. Findings in the latter population are inconsistent, however. Jensen et al. [27] examined the effectiveness of a multimodal intervention approach to falls prevention and found no effects on nursing home residents with Mini Mental State Examination Scores under 19.

\section{Improving cognitive performance}

Decline in cognitive performance, particularly in the domains of concentration and short-term memory, poses a significant risk to independence in old age [21]. Declines in speed of information processing that exceed the age norm are associated with increased risk for developing dementia disorders [37]. Cognitive training seems to be an important preventive approach in avoiding the need for care. Several research teams have presented evidence for the efficacy of cognitive activation in old age, both for normally aging people even in old very age and for elderly adults with symptoms of dementia [3, 11, 30, 36, 38]. For example, a (computer-based) training program targeting memory and information processing speed has been shown to have positive effects in nursing home residents [19]. According to a recent review [58], however, there are few empirically sound findings on the efficacy of psychosocial interventions that emphasize an emotional or cognitive approach (e.g., validation therapy or reality orientation in dementia) with respect to psychological or behavioral disorders that impede the provision of care.

Findings on the temporal stability of the outcomes of cognitive activation programs and the transfer of these effects to functions other than those targeted directly are inconsistent [10, 13]. Accordingly, it remains uncertain whether cognitive training might reduce the need for assistance with activities of daily living among elderly, multimorbid residents of nursing homes who already show cognitive impairment.

\section{Combination of physical and cognitive activation}

The question of whether a combination of psychomotor and cognitive activation might have synergetic effects, making such a combined approach more effective than each individual intervention alone, remains unanswered for residents of nursing homes. On the whole, neurophysiological studies $[6,15,28,48]$ support the assumption that the increased efficacy of combined training programs is attributable to a positive relationship between mental and physical activity and the functional capacity of brain cells. Empirical evidence shows that a combined activation program is more effective in community-dwelling older adults, at least. Specifically, the Maintaining and Supporting Independent Living in Old Age intervention study [SIMA, 38] for community-dwelling adults aged more than 75 years without care needs has shown that combined training of physical functioning (e.g., balance, speed) and cognitive functioning (information processing speed, attention and concentration, memory) is more effective than each individual approach separately. Furthermore, the combined training program proved to have transfer effects with respect to self and external ratings of independence and to mood. However, it remains to be seen whether this effect will also emerge in nursing home residents who already exhibit severe deficits in cognitive and functional performance and who have higher prevalence of symptoms of dementia than community-dwelling elderly adults.

Based on the intervention effects observed in the SIMA project, we thus developed a combined intervention program to improve psychomotor and cognitive functioning in multimorbid nursing home residents, some of whom already showed cognitive impairment. In a controlled study, we tested the assumption that a combination of cognitive and physical training significantly improves motor and cognitive performance and, in addition, has transfer effects in the form of decreased dependence on nursing staff and improvements in well-being.

\section{Intervention program}

The intervention program implemented thus comprises two components designed to train psychomotor skills (motor demands after Meusel [34]) and to promote cognitive activation. Each unit begins with about 20 min of physical 
exercise (psychomotor exercises, falls prevention), followed by $20-30 \mathrm{~min}$ of cognitive activation tasks, and ends with a 10-min relaxation section (e.g., listening to music or stories).

The intervention lasted 12 months, with 1-h group sessions being conducted twice a week. Each group consisted of eight participants on average (minimum six, maximum eight). The sessions were led by specially trained ergotherapists, who were given external supervision and who planned their approach in consultation with the study investigators. Detailed instructions on the scope and sequencing of exercises in all group sessions were provided in a training manual to ensure a standardized procedure in all treatment groups.

\section{Psychomotor activation}

The major points of intervention with respect to psychomotor skills and falls prevention are strength, stamina, suppleness, and coordination $[6,18,22,23,33,53,55,60]$. Becker et al. [5] and Kressig and Beauchet [31] found that exercises targeting these dimensions also had positive effects on dementia patients. The intervention program thus involves exercises such as diagonal movements of the extremities, throwing and catching a ball, or holding a balloon in the air (coordination), shifting body weight from side to side or walking on the spot (balance), working with modeling clay, alternately opening the hand and clenching it into a fist, leg lifts with strap-on weights or arm exercises with weights (strength), and seated dancing (coordination). Everyday movements (e.g., getting out of a chair, walking around the room) are also trained. Each unit begins with stretching and warming-up exercises and further includes psychomotor exercises to enhance physical experience (e.g., massage with a spiky massage ball), tactile experience (e.g., working with modeling clay), and social interaction (working in pairs and groups; cf. [14]).

\section{Cognitive activation}

The cognitive activation program implemented was adapted to participants' cognitive abilities. The training program developed for participants with a baseline score of more than 10 points on the Mini Mental State Examination [29] has its theoretical basis in a model of central information processing $[38,63]$. This approach distinguishes performance in the domains of attention and concentration, speed of information processing, and processing, storage, and retrieval of information in memory. The program involves digit or letter cancellation tasks (in which participants search for and cross out certain sequences of digits/letters in a row of digits/letters or in texts), maze tasks, free recall of stories that had been read aloud, and exercises designed to activate the contents of long-term memory (e.g., recognizing proverbs). Exercises aiming to stabilize or improve perceptual speed and ability are also implemented (e.g., identifying objects by touch, identifying noises).

In dementia patients with severe cognitive impairment, cognitive memory training can no longer be expected to have positive effects because cognitive plasticity is reduced [2, 47]. Accordingly, an alternative cognitive activation program was developed for participants scoring 10 or below on the Mini Mental State Examination, based primarily on biographical information, which remains intact for a comparatively long time in dementia patients. Heyn [26] found that a multisensory activation program (telling stories, imagination exercises, etc.) improved well-being, general levels of physical activity, and even coronary performance in a sample of nursing home residents with dementia. In the present study, stimulus material involved singing songs, listening to stories or fairy tales, activities with everyday objects, looking at photos, etc.

\section{Sample}

Bavaria's largest provider of care for the elderly permitted the study to be conducted in its nursing homes. To obtain a representative sample of residents, all 12 of the organization's nursing homes were included in the study. Residents who were not able to participate in group activities (i.e., who displayed disruptive behaviors such as shouting out and running away, or psychological disorders, such as psychotic symptoms or severe depressive episodes) were excluded from the study, as were residents with the following medical risk factors: venous thrombosis of the leg/phlebitis in the last 4 weeks, severe pulmonary hypertension, severe (instable) angina pectoris or coronary heart disease, heart attack in the last 3 months, a history of aortic stenosis or vascular aneurysm, severe cardiac disease with severe dyspnea or severe edema of the leg, and fractured vertebrae.

Of the 770 residents in the participating nursing homes, 415 met the psychiatric and medical criteria for participation. They were informed about the activation program in writing and in person and invited to participate. Because 201 of these residents were under legal guardianship, their guardians were also asked to give informed consent. A total of 333 residents agreed to participate in the study. Reasons given for nonparticipation were the time commitment involved or lack of interest.

Residents were not assigned to parallel treatment and control groups within the same nursing home in case the introduction of the intervention program prompted corresponding changes in the overall therapeutic approach of the nursing staff, such that control group members were 
Table 1 Development of the baseline sample

\begin{tabular}{ll}
\hline $\begin{array}{l}\text { Number of } \\
\text { cases }\end{array}$ & Description \\
\hline$N=770$ & Total population \\
$N=415$ & Met inclusion criteria \\
$N=333$ & Study sample (consented to participate) \\
$N=294$ & $\begin{array}{l}\text { Analysis sample at baseline ( } N=39 \text { participants } \\
\text { excluded to ensure that the treatment and control } \\
\end{array}$ \\
& group matched in terms of age) \\
\hline
\end{tabular}

also affected by the intervention. To prevent this possible confounding effect, treatment groups comprising a total of $N=171$ participants were formed in one set of homes, while $N=123$ residents of other homes made up the control group.

Because the mean ages of the treatment and control groups differed, $n=39$ residents were excluded from the study to ensure that the samples matched in terms of age. The study sample was thus reduced to $N=294$ participants at baseline (Table 1).

At baseline assessment, the treatment and control groups were comparable ( $t$ test; chi-square test) with respect to cognitive status (Mini Mental State Examination; MMSE), symptoms of depression (Geriatric Depressions Scale; GDS [61]), need for care (Neuropsychological Aging Observation Scale for Activities of Daily Living; GDS), and multimorbidity. There was, however, a significant difference in the gender distribution of the treatment and control groups at baseline but not in the sample used in the analyses (see Table 2). Overall, 157 members of the study sample dropped out over the 12-month intervention period, leaving a sample of $N=137$ participants at final assessment (start $N=294 ; 53 \%$ drop out). The results presented in this paper are based on this remaining sample.

Table 2 reports the baseline scores of the analysis sample members who did not drop out over the intervention period. There was no significant difference between the treatment and control groups in terms of mean age (83.06 vs
82.70 years; $p=0.772)$. The gender distribution was also comparable $(87.5 \%$ women in the treatment group; $76.7 \%$ in the control group; $p=0.078$ ). However, levels of activities of daily living, especially the need for care (GDS) and multimorbidity, were significantly higher in the control group than in the treatment group (25.8 vs $28.34, p=0.017$ and 4.96 vs $3.57, p=0.001$ ). Hence, the control did not differ in cognitive functions and depressive tendencies but showed a higher level of multimorbidity and consequently a higher need of care. Certainly these differences are the result of the exclusion of the participants in the treatment group which attended the treatment less than $30 \%$. The major reason of non-attendance was a low health status and chronic illness. These factors were highly correlated with multimorbidity.

\section{Study goals and methods}

The effects of the activation program were first tested in the domains it had been specifically designed to target, i.e., psychomotor skills, frequency of falls, and cognitive performance. We further investigated whether the intervention succeeded in reducing the amount of assistance needed with activities of daily living. Like cognitive impairment, negative psychological states, which are very prevalent in nursing homes, tend to be associated with need for assistance and to impede the provision of care. Accordingly, effects of the intervention program on residents' mood, as perceived by nursing staff, were also assessed. To further evaluate the program's effects on ward routine, a measure assessing occupational stress was administered to nursing staff.

The intervention was evaluated using psychometric methods, by consulting residents' care records, and by obtaining external ratings from nursing staff.

External ratings are particularly meaningful in the present study because they provide direct insights into any

Table 2 Analysis sample $(N=137)$

\begin{tabular}{|c|c|c|c|c|c|}
\hline \multirow[t]{2}{*}{ Variable } & \multicolumn{2}{|c|}{ Treatment $(N=64)$} & \multicolumn{2}{|c|}{ Control $(N=73)$} & \multirow[t]{2}{*}{$p$} \\
\hline & mean & $s$ & mean & $s$ & \\
\hline Age & 83.06 & 6.90 & 82.70 & 7.15 & 0.772 \\
\hline MMSE & 19.03 & 7.80 & 18.23 & 8.01 & 0.103 \\
\hline NAB & 25.80 & 6.60 & 28.34 & 5.84 & 0.017 \\
\hline GDS & 5.36 & 3.74 & 5.49 & 3.84 & 0.872 \\
\hline MMOSCO & 3.57 & 2.28 & 4.96 & 2.36 & 0.001 \\
\hline \multicolumn{6}{|l|}{ Gender } \\
\hline Male & 8 (absolute) & $12.5 \%$ & 17 (absolute) & $23.3 \%$ & 0.078 \\
\hline Female & 56 (absolute) & $87.5 \%$ & 56 (absolute) & $76.7 \%$ & \\
\hline
\end{tabular}

MMSE Mini Mental State Examination; NAB Neuropsychological Aging Observation Scale for Activities of Daily Living; GDS Geriatric Depression Scale; MMOSCO Multimorbidity Score reflecting the number of medical diagnoses listed in residents' care records 
reduction in the need for care and assistance that might have consequences for the provision of care.

To track the process of change as a result of the intervention, ratings were first obtained 6 months after the start of the intervention and again at its conclusion after a total of 12 months. In other words, change was monitored at 6-month intervals.

For participants with severe cognitive impairment (a score of 10 or below on the Mini Mental State Examination), external ratings only were used to assess the intervention's effects on cognitive performance and psychological well-being. The MMSE was the only psychometric instrument administered to this group for two reasons: first, these patients no longer have a sufficient understanding of test instructions and, second, their selfratings of psychological state can no longer be considered reliable.

Table 3 Overview of assessment instruments

Interpretation of Test Scores: plus sign, higher scores indicate improvements; minus sign, higher scores indicate declines
For all residents, data on frequency of falls and activities of daily living were obtained by consulting their care records and/or by means of external ratings.

Table 3 provides an overview of the instruments administered. Directions of test scores for interpretation of improvement or decline are also given in the table.

All assessment instruments with the exception of the nursing staff questionnaire meet the usual conditions and standards of reliability and validity. For specifics, refer to the cited original papers.

\section{Data analysis}

Because a normal distribution of scores and the necessary scale levels were not given for all variables under investigation, parametric procedures could not be applied.

\begin{tabular}{|c|c|c|}
\hline Goal criterion & Method of assessment & $\begin{array}{l}\text { Interpretation of } \\
\text { Test Scores }\end{array}$ \\
\hline \multirow[t]{6}{*}{$\begin{array}{l}\text { Psychomotor skills } \\
\text { and falls }\end{array}$} & $\begin{array}{l}\text { Modified Romberg Test (after Starischka [51]) } \\
\text { to assess static balance }\end{array}$ & + \\
\hline & $\begin{array}{l}\text { Chair-stand test (after Guralnik et al. [20]) to } \\
\text { assess lower body strength }\end{array}$ & - \\
\hline & $\begin{array}{l}\text { Chair sit-and-reach test (Light et al. [32]; Rikli } \\
\text { and Jones [41]) to assess trunk flexibility }\end{array}$ & - \\
\hline & $\begin{array}{l}\text { 2-min walk (after Rikli and Jones [41]) to assess } \\
\text { habitual walking speed, step continuity and } \\
\text { hesitancy (after Tinetti [56], Thiesemann et al. [54]) }\end{array}$ & + \\
\hline & External rating questionnaire administered to nursing staff &. \\
\hline & Residents' care records for information on falls & - \\
\hline \multirow[t]{2}{*}{$\begin{array}{l}\text { General cognitive } \\
\text { performance }\end{array}$} & $\begin{array}{l}\text { SIDAM (after Zaudig and Hiller [62]) including } \\
\text { the Mini Mental State Examination (after Folstein } \\
\text { et al. [16]). Both procedures are used to assess } \\
\text { dementia }\end{array}$ & + \\
\hline & $\begin{array}{l}\text { External rating questionnaire administered to } \\
\text { nursing staff }\end{array}$ & + \\
\hline \multirow[t]{4}{*}{$\begin{array}{l}\text { Specific aspects of } \\
\text { cognitive performance }\end{array}$} & $\begin{array}{l}\text { Subtests of the Neuropsychological Aging Inventory, } \\
\text { NAI (Oswald and Fleischmann [39]): }\end{array}$ & \\
\hline & Number Connection Test ZVT-G & + \\
\hline & $\begin{array}{l}\text { Memory Span ZN-G (repeating numbers forwards } \\
\text { and backwards) }\end{array}$ & + \\
\hline & Picture Test BT & + \\
\hline \multirow[t]{2}{*}{ Activities of daily living } & $\begin{array}{l}\text { Anamnesis questionnaire (based on operationalized } \\
\text { definitions: MDS/RAI-Version 2.0, } \\
\text { Garms-Homolova and Gilgen [17]) for activities } \\
\text { of daily living and other domains of life }\end{array}$ & - \\
\hline & $\begin{array}{l}\text { Neuropsychological Aging Observation Scale for } \\
\text { Activities of Daily Living, NAB (Oswald } \\
\text { and Fleischmann, [39]) to tap external ratings } \\
\text { of need for care }\end{array}$ & - \\
\hline $\begin{array}{l}\text { External ratings of need } \\
\text { for care }\end{array}$ & $\begin{array}{l}\text { External rating questionnaire administered to } \\
\text { nursing staff }\end{array}$ & + \\
\hline $\begin{array}{l}\text { Change in occupational } \\
\text { stress }\end{array}$ & Rated by nursing staff ("no change," "better," "worse") &. \\
\hline
\end{tabular}


Table 4 Dropout $(N=157)$ by group assignment

\begin{tabular}{|c|c|c|c|c|}
\hline \multirow[t]{2}{*}{ Group assignment } & \multicolumn{2}{|c|}{ Baseline sample } & \multicolumn{2}{|c|}{ Final sample } \\
\hline & Absolute & In $\%$ & Absolute & In $\%$ \\
\hline $\begin{array}{l}\text { Treatment: cognitive } \\
\text { activation }(\text { MMSE > 10) }\end{array}$ & 130 & 100 & 79 & 60.8 \\
\hline $\begin{array}{l}\text { Treatment: biography-based } \\
\text { activation }(\mathrm{MMSE} \leq 10)\end{array}$ & 41 & 100 & 28 & 68.3 \\
\hline Control (MMSE > 10) & 91 & 100 & 34 & 37.4 \\
\hline Control (MMSE $\leq 10)$ & 32 & 100 & 16 & 50.0 \\
\hline Total & 294 & 100 & 157 & 53.4 \\
\hline
\end{tabular}

We therefore used the nonparametric Mann-Whitney $U$ test to test for significant intervention effects between the baseline and final measurements. In each group, the differences between baseline and final assessment were calculated. Thereafter, the intra-group differences were tested between treatment and control on statistical significance. Furthermore, items with a significant between-group effect were tested with the Wilcoxon Test for related samples.

A two-tailed probability of $2 p=0.05$ was considered statistically significant. Two-tailed significance tests were used because we could not assume that the treatment group would outperform the control group throughout. Only participants who had attended at least $30 \%$ of the scheduled group sessions were included in the analyses.

We decided against an intent-to-treat analysis (ITT, last observation carried forward), in which the data of all participants are retained in the analysis regardless of dropout over the study period. Because it has to be assumed that the performance of samples of nursing home residents will not remain stable, but will decline gradually over time, this form of analysis would lead to artificially inflated results. Furthermore, maintaining the original sample size despite the decrease in actual participant numbers would lead to an increase in significant treatment effects.

\section{Findings}

Dropout analysis and analysis sample

Table 4 presents the dropout figures for the treatment and control groups.

Overall, dropouts were significantly older than continuers, with mean ages of 85.2 and 82.88 years, respectively ( $p=$ $0.003)$. There was no significant difference between continuers and dropouts in terms of mean baseline scores on the Mini Mental State Examination $(M=18.61$ vs $17.17 ; p=$ $0.137)$. The level of multimorbidity in the two groups was comparable ( 4.31 vs $4.52 ; p=0.475)$, as was the gender distribution ( 81.8 vs $87.9 \%$ woman, $p=0.145$ ).

Reasons for dropout are documented in Table 5. With the exception of motivational reasons, no significant differences were found between the treatment and control. The majority of dropouts for motivational reasons occurred in the first 4 weeks of the program, when a number of participants decided not to take part after all.

Intervention effects

Psychomotor skills and frequency of falls

Findings for psychomotor skills showed significant intervention effects with respect to strength and mobility (Changes within groups are shown in the footnote of Table 6). No significant differences relative to the control group were found for balance or stamina (Table 6). The test of balance proved problematic, however, in that many respondents were not prepared to adopt the tandem stance in the Romberg test for fear of falling.

The frequency of falls decreased significantly in the treatment group relative to the control group (Table 7). The absolute values reported are calculated on the basis of 100 residential care beds per 6 months. The underlying raw values are given in Table 7. The number of fallers per 100 beds

Table 5 Dropout from 0 to 12 months $(N=157)$

\begin{tabular}{|c|c|c|c|c|c|c|}
\hline \multirow[t]{2}{*}{ Reason for dropout } & \multicolumn{2}{|c|}{ Treatment group } & \multicolumn{2}{|c|}{ Control group } & \multicolumn{2}{|l|}{ Total } \\
\hline & Absolute & In $\%$ & Absolute & In $\%$ & Absolute & In $\%$ \\
\hline Death of participant & 33 & 30.9 & 25 & 50.0 & 58 & 36.9 \\
\hline Moved out of nursing home & 8 & 7.5 & 3 & 6.0 & 11 & 7.0 \\
\hline Deterioration in health status & 15 & 14.0 & 5 & 10.0 & 20 & 12.7 \\
\hline Motivational reasons & 26 & 24.3 & 8 & 16.0 & 34 & 21.7 \\
\hline Exclusion (for psychological/social reasons) & 4 & 3.7 & 9 & 18.0 & 13 & 8.3 \\
\hline Exclusion (low participation frequency) & 21 & 19.6 & - & - & 21 & 13.4 \\
\hline Total & 107 & 100 & 50 & 100 & 157 & 100 \\
\hline
\end{tabular}


Table 6 Functional Performance

\begin{tabular}{|c|c|c|c|c|c|c|c|c|c|c|}
\hline \multirow[b]{2}{*}{ Variables } & \multicolumn{3}{|c|}{ Total } & \multicolumn{3}{|c|}{ Treatment } & \multicolumn{3}{|c|}{ Control } & \multirow{2}{*}{$\frac{\mathrm{p}}{\text { Group Diff. } t_{0}-t_{12}}$} \\
\hline & $N$ & $\mathrm{t}_{0}$ mean $s$ & $t_{12}$ mean $s$ & $N$ & $\mathrm{t}_{0}$ mean $s$ & $t_{12}$ mean $s$ & $N$ & $\mathrm{t}_{0}$ mean $s$ & $t_{12}$ mean $s$ & \\
\hline Balance & 56 & 29.00 & 29.74 & 29 & 28.90 & 30.43 & 27 & 29.11 & 29.00 & 0.558 \\
\hline (Romberg test) & & 8.06 & 8.66 & & 8.34 & 9.08 & & 7.91 & 8.30 & \\
\hline Strength & 79 & 25.58 & 24.19 & 40 & 27.60 & 22.05 & 39 & 23.52 & 26.38 & $0.021^{*}$ \\
\hline (Chair-stand test) & & 12.52 & 11.26 & & 15.41 & 9.82 & & 8.33 & 12.31 & \\
\hline Mobility & 89 & 16.34 & 17.63 & 44 & 15.91 & 14.25 & 45 & 16.76 & 20.93 & $0.020 * *$ \\
\hline (Chair sit-and-reach test) & & 10.37 & 11.36 & & 10.45 & 10.19 & & 10.39 & 11.58 & \\
\hline Stamina & 87 & 69.03 & 67.83 & 45 & 68.90 & 71.00 & 42 & 69.18 & 64.42 & 0.260 \\
\hline (2-min walk) & & 32.20 & 32.51 & & 37.96 & 36.24 & & 25.06 & 28.00 & \\
\hline
\end{tabular}

*Intra-group differences: treatment $(p=0.126)$, control $(p=.100)$

** Intra-group differences: treatment $(p=0.447)$, control $(p=0.012)$

decreased by almost $58 \%$ in the treatment group, whereas the control group remained at baseline level (which was higher than in the treatment group). The frequency of falls per 100 beds also decreased, with "multiple fallers" deriving particular benefit from the training program. Whereas the number of falls decreased by some $70 \%$ in program participants, it increased by around $60 \%$ in the control group.

\section{Cognitive status}

Both the Mini Mental State Examination and the SISCO score, a global measure of cognitive performance/impairment, indicate that the general cognitive status of treatment group participants remained stable (Table 8 ), whereas that of control group members deteriorated significantly $(p=$ 0.001). Given the broad distribution of SISCO scores in the two groups, however, the difference between treatment and control group did not reach statistical significance.

Speed of information processing improved in the treatment group and declined in the control group. Here, again, scores were so widely distributed that the difference did not reach statistical significance.

In the domain of memory, no changes were discerned in passive retention (repeating numbers) in either the treatment or the control group. By contrast, there was a significant improvement in memory skills that involve dynamic encoding (picture test) in the treatment group. No such change was observed in the control group. In this test, the group difference became significant.
Activities of Daily Living (ADL)

Levels of independence in mobility and eating/dressing remained stable over the intervention period for the treatment group, but trend towards deterioration in the control group, however, the difference was not significant (see Table 9, footer). For mobility, the group-difference was significant. By contrast, no positive intervention effects were found for hygiene activities. The intervention did not have a favorable impact on the degree of continence or the need for assistance with bathing and showering (Table 9).

\section{External ratings by nursing staff}

Staff ratings of participants in the activation groups differed significantly and positively from their ratings of control home residents, who were not exposed to a specific intervention. Improvements were seen in residents' general health and physical status, cognitive performance (level of orientation to person, place, and time; communication; cognitive ability to cope with everyday demands), everyday mobility, and psychological mood. The nursing staff surveyed perceived improvements in $15-25 \%$ of treatment group members in these domains but deteriorations in 27 $43 \%$ of the control group members (Table 10).

In addition to rating the individual members of the treatment/control groups, the nursing staff were asked about changes in the overall ward environment. Highly significant differences between treatment and control homes emerged

Table 7 Fallers and frequency of falls per 100 residential care beds

\begin{tabular}{|c|c|c|c|c|c|c|c|}
\hline & \multicolumn{3}{|c|}{ Treatment } & \multicolumn{3}{|c|}{ Control } & \multirow{2}{*}{$\frac{\mathrm{p}}{x_{2}}$} \\
\hline & $N$ & $t_{0}$ number & $t_{12}$ number & $N$ & $t_{0}$ number & $t_{12}$ number & \\
\hline Fallers per 100 beds & $100^{\mathrm{a}}$ & 29.69 & 12.50 & $100^{\mathrm{b}}$ & 36.11 & 36.11 & $\mathrm{p}=0.006$ \\
\hline Frequency of falls per 100 beds & $100^{\mathrm{a}}$ & 103.13 & 29.69 & $100^{\mathrm{b}}$ & $\begin{array}{l}69.44 \\
\text { a base } 64 ;\end{array}$ & $\begin{array}{l}111.11 \\
73\end{array}$ & $\mathrm{p}=0.000$ \\
\hline
\end{tabular}


Table 8 Cognitive performance

\begin{tabular}{|c|c|c|c|c|c|c|c|c|c|c|}
\hline \multirow[b]{2}{*}{ Variables } & \multicolumn{3}{|c|}{ Total } & \multicolumn{3}{|c|}{ Treatment } & \multicolumn{3}{|c|}{ Control } & \multirow{2}{*}{$\frac{p}{\text { Group Diff. } t_{0}-t_{12}}$} \\
\hline & $N$ & $\mathrm{t}_{0}$ mean $s$ & $t_{12}$ mean $s$ & $N$ & $t_{0}$ mean $s$ & $t_{12}$ mean $s$ & $N$ & $t_{0}$ mean $s$ & $t_{12}$ mean $s$ & \\
\hline & 108 & 21.66 & 19.38 & 51 & 21.80 & 21.18 & 57 & 21.53 & 17.77 & $0.032 *$ \\
\hline MMSE & & 5.45 & 8.40 & & 5.60 & 7.35 & & 5.36 & 9.01 & \\
\hline \multirow[t]{3}{*}{ SISCO } & 108 & 34.76 & 31.77 & 51 & 35.71 & 34.80 & 57 & 33.91 & 29.05 & 0.214 \\
\hline & & 11.04 & 15.19 & & 11.30 & 13.90 & & 10.84 & 15.89 & \\
\hline & 71 & 82.25 & 79.72 & 36 & 85.72 & 77.06 & 35 & 78.69 & 82.46 & 0.272 \\
\hline \multirow[t]{2}{*}{ ZVT-G } & & 52.92 & 46.73 & & 64.20 & 50.08 & & 38.69 & 43.57 & \\
\hline & 89 & 8.78 & 8.29 & 45 & 8.67 & 8.09 & 44 & 8.89 & 8.50 & 0.514 \\
\hline \multirow[t]{2}{*}{$\mathrm{ZN}-\mathrm{G}$} & & 1.84 & 2.26 & & 2.02 & 2.54 & & 1.66 & 1.93 & \\
\hline & 82 & 3.48 & 3.82 & 42 & 3.57 & 4.29 & 40 & 3.38 & 3.33 & $0.029 * *$ \\
\hline BT & & 1.54 & 1.71 & & 1.65 & 1.71 & & 1.43 & 1.58 & \\
\hline
\end{tabular}

MMSE Mini Mental State Examination; SISCO SIDAM score; ZVT-G Number Connection Test; ZN-G Memory Span; BT Picture Test

*Intra-group differences: treatment $(p=0.395)$, control $(p=0.001)$

**Intra-group differences: treatment $(p=0.009)$, control $(p=0.912)$

here (Table 11). In general, the nursing staff in the intervention homes perceived residents to be more independent in everyday life and to show higher levels of psychological well-being and mental alertness than before the activation program. Moreover, they rated occupational stress to be reduced and their interactions with residents to be easier. It can thus be assumed that the intervention program had positive effects on the ward environment as a whole. As the interventions were implemented in the nursing wards, it was not possible to blind the nursing staff about the treatments. Hence, some of the staff members were informed about the attendance of the residents, others were not.

\section{Discussion}

Residents of nursing homes for the elderly typically have multiple impairments affecting their cognitive abilities, physical functioning, ability to perform the activities of daily living unassisted, and psychological well-being. Accordingly, rehabilitative care does not focus on specific medical diagnoses but is designed to meet diverse functional, cognitive, and psychosocial support needs [12]. Interventions targeting these areas can help to delay or inhibit the increasing dependence on care and to ensure that aged adults maintain functional independence in performing the activities of daily living to the greatest possible degree.

Building on research showing that a combination of physical and cognitive training is more effective than each individual treatment alone in maintaining the independence of community-dwelling elderly adults [38], the present controlled study investigated the effects of a combined physical and cognitive activation program in residents of nursing homes. Given that nursing home residents typically show multiple impairments, we tested the effects of the intervention program on various levels: physical performance and falls prevention, cognitive performance, activities of daily living, and psychological well-being.

The 1-year intervention program, which incorporated simple exercises to improve strength, suppleness, and stamina, led to significant improvements in physical performance. Thus, our results extend previous empirical

Table 9 Changes in ADL

\begin{tabular}{|c|c|c|c|c|c|c|c|c|c|c|}
\hline \multirow[b]{2}{*}{ Variables } & \multicolumn{3}{|c|}{ Total } & \multicolumn{3}{|c|}{ Treatment } & \multicolumn{3}{|c|}{ Control } & \multirow{2}{*}{$\frac{p}{\text { Group Diff. } t_{0}-t_{12}}$} \\
\hline & $N$ & $\mathrm{t}_{0}$ mean $s$ & $t_{12}$ mean $s$ & $N$ & $\mathrm{t}_{0}$ mean $s$ & $t_{12}$ mean $s$ & $N$ & $\mathrm{t}_{0}$ mean $s$ & $t_{12}$ mean $s$ & \\
\hline ADL & 107 & 1.67 & 1.79 & 51 & 1.63 & 1.57 & 56 & 1.71 & 1.98 & $0.020^{*}$ \\
\hline Mobility & & 0.92 & 0.97 & & 0.87 & 0.83 & & 0.97 & 1.05 & \\
\hline $\mathrm{ADL}$ & 107 & 2.17 & 2.37 & 51 & 2.14 & 2.22 & 56 & 2.20 & 2.52 & $0.060 * *$ \\
\hline Eating/dressing & & 1.12 & 1.01 & & 1.11 & 1.01 & & 1.13 & 1.01 & \\
\hline $\mathrm{ADL}$ & 107 & 2.09 & 2.13 & 51 & 2.00 & 2.00 & 56 & 2.18 & 2.25 & 0.527 \\
\hline Hygiene & & 1.17 & 0.97 & & 1.08 & 0.89 & & 1.25 & 1.03 & \\
\hline
\end{tabular}

*Intra-group differences: treatment $(p=0.247)$, control $(p=0.089)$

$* *$ Intra-group differences: treatment $(p=0.816)$, control $(p=0.047)$ 
Table 10 External ratings of individual residents by nursing staff $(N=122)$

\begin{tabular}{|c|c|c|c|c|c|c|c|c|}
\hline \multirow[t]{2}{*}{ Dimension } & & \multicolumn{2}{|l|}{ Worse } & \multicolumn{2}{|c|}{ No Change } & \multicolumn{2}{|l|}{ Better } & \multirow[t]{2}{*}{$p$} \\
\hline & & Absolute & In $\%$ & Absolute & In $\%$ & Absolute & In $\%$ & \\
\hline \multirow[t]{2}{*}{ General status } & Treatment & 8 & 13.6 & 36 & 61.0 & 15 & 25.4 & \multirow[t]{2}{*}{0.003} \\
\hline & Control & 24 & 38.1 & 33 & 52.4 & 6 & 9.5 & \\
\hline \multirow[t]{2}{*}{ Cognitive performance } & Treatment & 5 & 8.5 & 45 & 76.3 & 9 & 15.3 & \multirow[t]{2}{*}{0.000} \\
\hline & Control & 27 & 42.9 & 34 & 54.0 & 2 & 3.2 & \\
\hline \multirow[t]{2}{*}{ Mobility } & Treatment & 13 & 22.0 & 37 & 62.7 & 9 & 15.3 & \multirow[t]{2}{*}{0.057} \\
\hline & Control & 25 & 39.7 & 34 & 54.0 & 4 & 6.3 & \\
\hline \multirow[t]{2}{*}{ Psychological mood } & Treatment & 4 & 6.8 & 41 & 69.5 & 14 & 23.7 & \multirow[t]{2}{*}{0.002} \\
\hline & Control & 17 & 27.0 & 41 & 65.1 & 5 & 7.9 & \\
\hline
\end{tabular}

findings on the positive effects of physical training in individuals in need of care [31, 46, 59] to a sample of elderly and multimorbid nursing home residents. In contrast to previous studies [5,57], however, no improvements were observed in balance ability. A possible reason for this finding is that psychomotor exercises were performed seated in the present study to ensure that participants were not put at any unnecessary risk. Clearly, this approach will not produce maximum improvements in balance ability. Second, balance ability was measured using the modified Romberg test after Starischka [51]. Although almost all participants were able to perform the test in the semitandem stance, most of them did not complete the tandem stance because they felt unsteady or afraid of falling. It is thus conceivable that changes over time were not properly measured.

Nevertheless, the intervention program resulted in a significant reduction in the frequency of falls, with multiple fallers deriving particular benefits. These findings substantiate the results of other studies showing that physical activation can decrease the risk of falls even in elderly adults who already show impairment $[22,35]$.

A reduction in the frequency of falls was also observed in respondents with dementia - in contrast to Jensen et al. [27], who did not find any training effects in nursing home residents with lower cognition scores. It thus seems likely that the extension of these effects to cognitively impaired participants can be attributed to the combination of psychomotor and cognitive activation implemented in the present study. Cognitive impairment is a significant risk factor for falls. The cognitive activation component of the present intervention increased the effectiveness of the psychomotor activation component with respect to falls prevention by enhancing the cognitive capacities needed to prevent falls (general alertness, attention).

The reports of the nursing staff further suggest that the improvements observed in motor and cognitive functioning have transfer effects that can be observed in everyday life, a finding that contrasts with previous reports [24, 42]. Our results seem to suggest that only long-term activation programs have transfer effects - our intervention program lasted 12 months, compared with 3-6 months in previous studies. Hauer et al. [24] also showed that changes in functional performance can only be maintained by longterm, continuous training and that physical performance otherwise drops back to baseline level after rehabilitation.

The nursing staff also reported improvements in participants' cognitive activation and alertness, as well as positive effects on everyday behavior and activities of daily living.

Table 11 External ratings of the overall ward environment by nursing staff

\begin{tabular}{|c|c|c|c|c|c|c|c|c|}
\hline \multirow[t]{2}{*}{ Dimension } & & \multicolumn{2}{|l|}{ Worse } & \multicolumn{2}{|c|}{ No Change } & \multicolumn{2}{|l|}{ Better } & \multirow[t]{2}{*}{$p$} \\
\hline & & Absolute & In $\%$ & Absolute & In $\%$ & Absolute & In $\%$ & \\
\hline \multirow[t]{2}{*}{ Independence (ADL) } & Treatment & 25 & 30.1 & 37 & 44.6 & 21 & 25.3 & \multirow[t]{2}{*}{$<0.001$} \\
\hline & Control & 60 & 45.8 & 62 & 47.3 & 9 & 6.9 & \\
\hline \multirow[t]{2}{*}{ Psychological well-being } & Treatment & 17 & 20.4 & 32 & 38.6 & 34 & 41.0 & \multirow[t]{2}{*}{$<0.001$} \\
\hline & Control & 39 & 29.8 & 75 & 57.3 & 17 & 12.9 & \\
\hline \multirow[t]{2}{*}{ Mental alertness } & Treatment & 15 & 18.1 & 31 & 37.3 & 37 & 44.6 & \multirow[t]{2}{*}{0.002} \\
\hline & Control & 40 & 30.5 & 64 & 48.9 & 27 & 20.6 & \\
\hline \multirow[t]{2}{*}{ Occupational stress } & Treatment & 40 & 48.2 & 31 & 37.3 & 12 & 14.5 & \multirow[t]{2}{*}{$<0.001$} \\
\hline & Control & 101 & 77.1 & 24 & 18.3 & 6 & 4.6 & \\
\hline \multirow[t]{2}{*}{ Interactions with residents } & Treatment & 13 & 15.7 & 38 & 45.8 & 32 & 38.6 & \multirow[t]{2}{*}{$<0.001$} \\
\hline & Control & 52 & 39.7 & 55 & 42.0 & 24 & 18.3 & \\
\hline
\end{tabular}


Previous studies have already shown that the cognitive performance of nursing home residents can be improved by means of training programs [19]. The present study extends these findings to show that activation programs also impact everyday activities, even in dementia patients. In other words, providing activation programs for nursing home residents with severe cognitive impairment has beneficial effects not only for well-being and physical functioning [26] but also for behavior.

Given that our psychometric tests of memory only found effects on visual memory, the positive effect of cognitive activation seems primarily attributable to the improvements measured in speed of information processing and/or to the increase observed in general alertness and responsiveness. The latter is significantly related to independence in performing activities of daily living [37]; thus, measures targeting general alertness have a key role to play as a regular component of cognitive activation programs.

The activation program had direct significant and lasting effects on some activities of daily living, at least. Effects were seen in the domains of mobility and eating/dressing but not in hygiene activities. Here, it is important to bear in mind that the intervention had no direct influence on the ward environment as such and that, within the existing structures, residents' opportunities for independent behavior remained limited. In other words, although the intervention succeeded in enhancing the physical and cognitive capacities needed to maintain independence in performing activities of daily living, there was no corresponding change in behavior in the nursing home environmentmore specifically, in the behavior of the nursing staff. Against this background, nursing staff reports indicating that residents had become more likely to help with activities of daily living or to perform these independently are particularly meaningful. Transfer effects to everyday behavior can be assumed in this respect, at least. Furthermore, the nursing staff rated the psychological well-being of members of the treatment group to be significantly higher than that of members of the control group, even in residents with dementia.

The nursing staff evidently also associated residents' enhanced levels of activity and mental alertness with positive psychological mood and perceived interaction with the residents to be easier. Heyn [26] also reported positive effects of activation on the psychological well-being of persons with dementia.

However, the results of the present study show that the potential for positive change in patients already experiencing severe loss of independence is limited, particularly in specific domains of cognitive performance where no significant training effects were found. Multimorbidity also limits the potential for rehabilitation; participants frequently missed training sessions owing to acute illness. Furthermore, the steady decline in performance over the interven- tion period in control group members, who scored lower than treatment group members on multimorbidity and activities of daily living at baseline, indicates that nursing home residents with a low baseline level of performance are at high risk for increasing need for care. The improvements observed in the treatment group indicate that activating interventions should be initiated soon after admission to a nursing home, at a relatively high level of functioning, if further losses are to be delayed or diminished. The later rehabilitation measures are initiated, the less likely it seems to be that they will succeed. The earlier they begin, the longer activating measures can be implemented as part of the care routine and the more likely it is that intervention effects will be observed [24].

The nursing staff reports indicate that the activation program for residents of nursing homes had positive overall effects on the ward environment and boosted staff job satisfaction. In other words, the present activation program can also enhance the workday routine and job satisfaction of nursing care professionals. The design of the activation program is such that it can be administered by nursing staff given special training. The improvements observed in the ward environment and in residents' cognitive and psychological status might be further enhanced by involving nursing staff directly in the intervention program, in other words, by extending their responsibilities from patient care to active rehabilitation. Whether closer involvement of nursing staff in the activation program can further promote the activation of nursing home residents must remain a subject for future research. However, the present study already shows that nursing staff have positive attitudes to activation programs that take a rehabilitative approach.

\section{References}

1. Ackermann A, Oswald WD (2006) Erhalt und Förderung der Selbstständigkeit bei Pflegeheimbewohnern-Ein Überblick über bestehende Ansätze. Z Gerontopsychol Psychiatr 19:59-71

2. Auffray C, Juhel J (2001) Effets généraux et différentiels d'un programme d'entraînement cognitif multimodal chez la personne âgée. Année Psychol 101:65-89

3. Ball K, Berch DB, Helmers KJ, Jobe JB, Leveck MD, Marsiske M, Morris JN, Rebok GW, Smith DM, Tennstedt SL, Unverzagt FW, Willis SL (2002) Effects of cognitive training interventions with older adults A randomized controlled trial. JAMA 288:2271-2281

4. Bean JF, Kiely DK, Herman S, Leveille SG, Mizer K, Frontera WR, Fielding RA (2002) The relationship between leg power and physical performance in mobility. J Am Geriatr Soc 50:461-467

5. Becker C, Lindemann U, Kapfer E, Nikolaus T (2000) Verminderung von sturzbedingten Verletzungen bei Alten- und Pflegeheimbewohnern. 2 Jahresbericht des Ulmer Modellvorhabens "Mobilität und Mobilitätsstörungen von Heimbewohnern". KDA, Berlin

6. Bennett EL, Diamond MC, Krech D, Rosenzweig MR (1996) Chemical and anatomical plasticity of brain. J. Neuropsychiatry 8:459-470 (First published in Science 1964, 146:610-619) 
7. Carlson JE, Ostir GV, Black SA, Markides KS, Rudkin L, Goodwin JS (1999) Disability in older adults 2: Physical activity as prevention. Behav Med 24:157-168

8. Carter ND, Kannus P, Khan KM (2001) Exercise in the prevention of falls in older people: A systematic literature review examining the rationale and the evidence. Sports Med 31:427-438

9. Chiodo LK, Gerety MB, Mulrow CD, Rhodes MC, Tuley MR (1992) The impact of physical therapy on nursing home patients' outcomes. Phys Ther 72:168-173

10. Clare L, Woods RT, Moniz Cook ED, Orrell M, Spector A (2003) Cognitive rehabilitation and cognitive training for early-stage Alzheimer's disease and vascular dementia. Cochrane Database Syst Rev 4:CD003260

11. Colcombe SJ, Kramer AF (2003) Fitness effects on the cognitive function of older adults: A meta-analytic study. Psychol Sci 14:125-130

12. Dangel B, Korporal J (2003) Kann Pflege im Rahmen der Pflegeversicherung Grundlage eines spezifischen pflegerischen Ansatzes der Rehabilitation sein? Z Gerontol Geriatr 36:50-62

13. Davies RN, Massmann PJ, Doody RS (2001) Cognitive intervention in Alzheimer Disease: A randomized placebo-controlled study. Alzheimer Dis Assoc Disord 15:1-9

14. Eisenburger M (1999) Psychomotorik im Alten- und Pflegeheim Institut für Bewegungsbildung und Psychomotorik Internetzeitschrift des Forums Psychomotorik [http://wwwibp-psychomotorikde]

15. Eriksson PS, Perfilieva E, Björk-Eriksson T, Alborn AM, Nordborg C, Peterson D, Gage FH (1998) Neurogenesis in the adult human hippocampus. Nat Med 4:1313-1317

16. Folstein MF, Folstein SE, McHugh PR (1975) "Mini-Mental State": A practical method for grading the cognitive status of patients for the clinician. J Psychiatr Res 12:189-198

17. Garms-Homolova V, Gilgen R (2000) Resident Assessment Instrument (RAI) 20 (2nd revised and extended edn) Huber, Bern

18. Gillespie LD, Gillespie WJ, Robertson MC, Lamb SE, Cumming RG, Rowe BH (2001) Interventions for preventing falls in elderly people. Cochrane Database Syst Rev 3: CD000340

19. Günther VK, Schäfer P, Holzner BJ, Kemmler GW (2003) Longterm improvements in cognitive performance through computerassisted cognitive training: a pilot study in a residential home for older people. Aging Ment Health 7:200-206

20. Guralnik JM, Simonsick EM, Ferrucci L, Glynn RJ, Berkman LF, Blazer DG (1994) A short physical performance battery assessing lower extremity function: association with self-reported disability and prediction of mortality and nursing home admission. $\mathrm{J}$ Gerontol 49:M85-94

21. Hagen B, Oswald WD, Gunzelmann T, Rupprecht R (2002) Bedingungen der Erhaltung und Förderung von Selbstständigkeit im höheren Lebensalter (SIMA) - Teil XIX: Unselbstständigkeitsrisiken aus der Perspektive unterschiedlicher Selbstständigkeitsdefinitionen. Z Gerontopsychol Psychiatr 15:139-160

22. Haines TP, Bennell KL, Osborne RH, Hill KD (2004) Effectiveness of targeted falls prevention programme in subacute hospital setting: randomised controlled trial. Br Med J 328:676-679

23. Hauer K, Rost B, Rutschle K, Opitz H, Specht N, Bartsch P, Oster P, Schlierf G (2001) Exercise training for rehabilitation and secondary prevention of falls in geriatric patients with a history of injurious falls. J Am Geriatr Soc 49:10-20

24. Hauer K, Pfisterer M, Schuler M, Bartsch P, Oster P (2003) Two years later: a prospective long-term follow-up of a training intervention in geriatric patients with a history of severe falls. Arch Phys Med Rehabil 84:1426-1432

25. Heruti RJ, Lusky A, Dankner R, Ring H, Dolgopiat M, Barell V, Levenkrohn S, Adunsky A (2002) Rehabilitation outcome of elderly patients after a first stroke: effect of cognitive status at admission on the functional outcome. Arch Phys Med Rehabil 83:742-749
26. Heyn P (2003) The effect of a multisensory exercise program on engagement behaviour and selected physiological indexes in persons with dementia. Am J Alzheimer's Dis Other Dement $18: 247-251$

27. Jensen J, Nyberg L, Gustafson Y, Lundin-Olsson L (2003) Fall and injury prevention in residential care-effects in residents with higher and lower levels of cognition. J Am Geriatr Soc 51:627-635

28. Kempermann G, Kuhn HG, Gage FH (1999) More hippocampal neurons in adult mice living in an enriched environment. Nature 386:493-495

29. Kessler J, Markowitsch HJ, Denzler PE (1990) MMST: MiniMental-Status-Test. Beltz Test GmbH, Weinheim

30. Kramer AF, Willis SL (2003) Cognitive plasticity and aging In: Ross B (ed) Psychology of learning and motivation. Academic, New York, pp 43-47

31. Kressig RW, Beauchet O (2004) Die Rolle der Ganganalyse in therapeutischen Trainingsprogrammen von Betagten. Z Gerontol Geriatr 37:15-19

32. Light KE, Purser JL, Rose DK (1995) The functional reach test for balance: criterion-related validity of clinical observations. Am Phys Ther Assoc 18:5-9

33. McCarthy ME (2003) Getting a lift from lifting Weight training can effectively improve strength mobility and ultimately independence for even very old frail adults. American Health Care Association, Washington, DC

34. Meusel H (2004) Bewegung und Sport In: Kruse A, Martin M (eds) Enzyklopädie der Gerontologie. Alternsprozesse in multidisziplinärer Sicht. Verlag Hans Huber, Bern, pp 255-272

35. Moreland JD, Richardson JR, Goldsmith CH, Clase CM (2004) Muscle weakness and falls in older adults: systematic review and meta-analysis. J Am Geriatr Soc 52:1121-1129

36. Oswald WD (2004) Kognitive und körperliche Aktivität: Ein Weg zur Erhaltung von Selbstständigkeit und zur Verzögerung demenzieller Prozesse? Z Gerontopsychol Psychiatr 17:147-159

37. Oswald WD, Hagen B, Rupprecht R, Gunzelmann T, Steinwachs KC (2002) Bedingungen der Erhaltung und Förderung von Selbstständigkeit im höheren Lebensalter (SIMA) Teil XVIII: Unselbstständigkeits- Demenz- und Mortalitätsrisiken. Z Gerontopsychol Psychiatr 15:61-84

38. Oswald WD, Hagen B, Rupprecht R, Gunzelmann T (2002) Bedingungen der Erhaltung und Förderung von Selbstständigkeit im höheren Lebensalter (SIMA) Teil XVII: Zusammenfassende Darstellung der langfristigen Trainingseffekte. Z Gerontopsychol Psychiatr 15:13-31

39. Oswald WD, Fleischmann UM (1999) Nürnberger-Alters-Inventar (NAI). Hogrefe Verlag für Psychologie, Göttingen

40. Richardson J, Bedard M, Weaver B (2001) Changes in physical functioning in institutionalized older adults. J Men Health Aging 23:683-689

41. Rikli RE, Jones JC (2001) Senior fitness test manual. Human Kinetics, Champaign, IL

42. Rolland $\mathrm{Y}$, Rival L, Pillard F, Lafont $\mathrm{C}$, Rivère $\mathrm{D}$, Albarède $\mathrm{J}$, Vellas B (2000) Feasibility of regular physical exercise for patients with moderate to severe Alzheimer's Disease. J Nutr Health Aging 4:109-113

43. Schaeffer D, Wingenfeld K (2004) Pflegerische Versorgung alter Menschen. In: Kruse A, Martin M (eds) Enzyklopädie der Gerontologie. Alternsprozesse in multidisziplinärer Sicht. Verlag Hans Huber, Bern, pp 477-490

44. Schnelle JF, MacRae PG, Giacobassi K, MacRae H, Simmons SF, Ouslander JG (1996) Exercise with physically restrained nursing home residents: Maximizing benefits of restraining reduction. J Am Geriatr Soc 44:507-512

45. Sieri T, Beretta G (2004) Fall risk assessment in very old males and females living in nursing homes. Disabil Rehabil 26:718-723 
46. Sihvonen SE, Sipilä S, Era PA (2004) Changes in postural balance in frail elderly women during a 4-week visual feedback training: a randomized controlled trial. Gerontology 50:87-95

47. Singer T, Lindenberger U, Baltes PB (2003) Assessment and treatment of nursing home residents with depression or behavioral symptoms associated with dementia: a review of the literature. J Am Geriatr Soc 51:1305-1317

48. Spatz HC (1996) Hebb's concept of synaptic plasticity and neuronal cell assemblies. Behav Brain Res 78:3-7

49. Specht-Leible N, Bender M, Oster P (2003) Die Ursachen der stationären Aufnahme von Alten- und Pflegeheimbewohnern in einer geriatrischen Klinik. Z Gerontol Geriatr 36:274-279

50. Spirduso WW, Cronin DL (2001) Exercise dose-response effects on quality of life and independent living in older adults. Med Sci Sports Exerc 33:598-608

51. Starischka S (1991) Altern und Sport. Band 1. SFT, Erlensee

52. Stuck AE, Walthert JM, Nikolaus T, Buela CJ, Hohmann C, Beck JC (1999) Risk factors for functional status decline in community-living elderly people: a systematic literature review. Soc Sci Med 48:445-469

53. Sullivan DH, Wall PT, Bariola JR, Bopp MM, Frost YM (2001) Progressive resistance muscle strength training of hospitalized frail elderly. Am J Phys Med Rehabil 80:503-509

54. Thiesemann R, Renteln-Kruse W von, Meins W, Tuschick B, Vogel J, Meier-Baumgartner HP (1997) Der Mobilitätstest nach Tinetti: Änderungssensitivität der Gangbeurteilung im Verlauf geriatrischer Krankenhausbehandlung-Aspekte der klinischen Relevanz und Qualitätssicherung. Z Gerontol Geriatr 30:281-288

55. Timonen L, Rantanen T, Timonen TE, Sulkava R (2002) Effects of a group-based exercise program on the mood state of frail older women after discharge from hospital. Int J Geriatr Psychiatry 17:1106-1111
56. Tinetti ME (1994) Prevention of falls and fall injuries in elderly persons: a research agenda. Prev Med 23:756-762

57. Tinetti ME, Baker DI, Gottschalk M, Williams CS, Pollack D, Garrett P, Gill TM, Marottoli RA, Acampora D (1999) Home-based multicomponent rehabilitation program for older persons after hip fracture: a randomized trial. Arch Phys Med Rehabil 80:916-922

58. Verkaik R, van Weert JCM, Francke AL (2005) The effects of psychosocial methods on depressed aggressive and apathetic behaviors of people with dementia: A systematic review. Int J Geriatr Psychiatry 20:301-314

59. Visser M, Pluijm SMF, Stel VS, Bosscher RJ, Deeg DJH (2002) Physical activity as a determinant of change in mobility performance: the longitudinal aging study Amsterdam. J Am Geriatr Soc 50:1774-1781

60. Wolf B, Feys H, de Weerdt W, van der Meer J, Noom M, Aufdemkampe G (2001) Effect of a physical therapeutic intervention for balance problems in the elderly: a single-blind randomized controlled multicentre trial. Clin Rehabil 15:624-636

61. Yesavage JA, Brink TL, Rose TL, Lum O, Huang V, Adey M, Leirer VO (1983) Development and validity of a Geriatric Depression Screening Scale: A preliminary report. J Psychiatr Res 17:37-49

62. Zaudig M, Hiller W (1996) SIDAM-Handbuch. Strukturiertes Interview für die Diagnose einer Demenz vom Alzheimer Typ der Multiinfarkt- (oder vaskulären) Demenz und Demenzen anderer Ätiologie nach DSM-IV und ICD-10. Hogrefe Verlag für Psychologie, Göttingen

63. Zimprich D (2004) Kognitive Leistungsfähigkeit im Alter In: Kruse A, Martin M (eds) Enzyklopädie der Gerontologie Alternsprozesse in multidisziplinärer Sicht. Verlag Hans Huber, Bern, pp 289-303 